\title{
Granulocyte macrophage colony-stimulating factor as a predictor of the response of metastatic renal cell carcinoma to tyrosine kinase inhibitor therapy
}

\author{
DAISUKE YAMADA ${ }^{1}$, HIROKAZU MATSUSHITA ${ }^{2}$, TAKESHI AZUMA ${ }^{3}$, TOHRU NAKAGAWA $^{3}$, \\ MASAYOSHI NAGATA ${ }^{4}$, YUKIO YAMADA ${ }^{3}$, MOTOFUMI SUZUKI ${ }^{4,5}$, TETSUYA FUJIMURA ${ }^{3}$, \\ HIROSHI FUKUHARA ${ }^{3}$, HARUKI KUME ${ }^{3}$, YUKIO HOMMA ${ }^{3}$ and KAZUHIRO KAKIMI ${ }^{2}$
}

\author{
${ }^{1}$ Department of Urology, Chibanishi General Hospital, Matsudo, Chiba 270-2251; Departments of ${ }^{2}$ Immunotherapeutics \\ and ${ }^{3}$ Urology, University of Tokyo Hospital, Tokyo 113-8655; ${ }^{4}$ Department of Urology, National Center for Global \\ Health and Medicine, Tokyo 162-8655; ${ }^{5}$ Department of Urology, Tokyo Teisin Hospital, Tokyo 102-8798, Japan
}

Received June 12, 2014; Accepted July 7, 2014

DOI: $10.3892 / \mathrm{mco} .2014 .360$

\begin{abstract}
This prospective study was conducted to identify predictive markers for the response of metastatic renal cell carcinoma (RCC) to tyrosine kinase inhibitors (TKIs). Patients with histologically proven RCC with at least one measurable metastatic lesion were enrolled in this study. Blood samples were collected prior to treatment and the plasma levels of 27 cytokines were measured. Tumor response was assessed 8-12 weeks after the initiation of TKI treatment. A total of 13 patients (11 men and 2 women) with a median age of 63 years received sunitinib (8 cases), sorafenib (1 case), or axitinib (4 cases). Partial response (PR) was achieved in 5 patients (38\%), stable disease (SD) in $4(30 \%)$ and progressive disease (PD) was noted in $4(30 \%)$. The plasma granulocyte macrophage colony-stimulating factor (GM-CSF) level in PR cases was significantly higher compared to that in SD or PD cases $(\mathrm{P}=0.012)$. Therefore, GM-CSF may be a predictive biomarker of the response of RCC to TKI treatment, suggesting that TKIs may exert clinical effects not only through suppression of the vascular endothelial growth factor, but also through immune system modulation.
\end{abstract}

\section{Introduction}

Renal cell carcinoma (RCC) is one of the major causes of cancer-related mortality. There were an estimated $\sim 64,700$ new cases of RCC and 13,570 deaths in 2012 in the United States (1). Over the last few years, a number of tyrosine kinase inhibitors (TKIs) have been proven to be effective and are currently widely used for the treatment of metastatic RCC.

Correspondence to: Dr Haruki Kume, Department of Urology, University of Tokyo Hospital, 7-3-1 Hongo, Bunkyo-ku, Tokyo 113-8655, Japan

E-mail:kume@kuc.biglobe.ne.jp

Key words: metastatic, renal cell carcinoma, tyrosine kinase inhibitors, granulocyte macrophage colony-stimulating factor
However, the effect of these TKIs appears to be rather limited, with only $31 \%$ of naive cases exhibiting an objective response [complete response (CR) or partial response (PR)] to sunitinib treatment in the first-line setting (2) and only $10 \%$ of cases with previous cytokine therapy exhibiting a PR to treatment with sorafenib (3). However, thus far, only a limited number of factors that predict the response of RCC to TKIs have been reported. A significant decrease in serum vascular endothelial growth factor (VEGF) receptor-2 levels and/or an increase in serum VEGF levels were observed in patients exhibiting an objective tumor response $(4,5)$. Hypothyroidism and hypertension associated with TKI treatment were also reported to be correlated with a favorable response $(6,7)$.

Although previous studies suggested that TKIs may affect the immune system $(8,9)$, only a limited number of studies have investigated immunological biomarkers for therapeutic prediction. Adotevi et al (10) reported that a decrease in regulatory $\mathrm{T}$ cells was correlated with a favorable overall survival in cases with metastatic RCC who received sunitinib-based antiangiogenic therapy. Thus, we conducted a prospective study to invesigate predictive immunological biomarkers.

\section{Patients and methods}

Patients. Patients with histologically proven RCC with at least one measurable metastatic lesion, who were diagnosed between March, 2012 and June, 2013, were enrolled in this study. Sunitinib, sorafenib or axitinib were administered orally as previously described $(2,3,11)$. Tumor response was assessed 8-12 weeks after the initiation of TKI treatment according to the response evaluation criteria in solid tumors and was classified as CR, PR, stable disease (SD) or progressive disease (PD) (12).

We collected blood samples from the 13 patients prior to treatment. The plasma was deep frozen at $-80^{\circ} \mathrm{C}$ and stored before measuring the immune function.

Cytokines. A total of 27 cytokines including interleukin (IL)-1 $\beta$, IL-1ra, IL-2, IL-4, IL-5, IL-6, IL-7, IL-8, IL-9, 
Table I. Correlation between the clinical effect of tyrosine kinase inhibitors (TKIs) and clinicopathological characteristics among patients with metastatic renal cancer.

\begin{tabular}{|c|c|c|c|c|c|}
\hline \multirow[b]{2}{*}{ Clinical characteristics } & \multirow[b]{2}{*}{$\begin{array}{c}\text { Total } \\
(n=13)\end{array}$} & \multicolumn{3}{|c|}{ Clinical effect ${ }^{\mathrm{a}}$} & \multirow[b]{2}{*}{ P-value } \\
\hline & & $\begin{array}{c}\text { PR } \\
(n=5)\end{array}$ & $\begin{array}{c}\mathrm{SD} \\
(\mathrm{n}=4)\end{array}$ & $\begin{array}{c}P D \\
(n=4)\end{array}$ & \\
\hline \multicolumn{6}{|l|}{ Gender } \\
\hline Male & 11 & 4 & 4 & 3 & 0.603 \\
\hline Female & 2 & 1 & 0 & 1 & \\
\hline \multicolumn{6}{|l|}{ Age (years) } \\
\hline$\geq 65$ & 7 & 2 & 2 & 3 & 0.593 \\
\hline$<65$ & 6 & 3 & 2 & 1 & \\
\hline \multicolumn{6}{|l|}{ Performance status } \\
\hline 0 & 8 & 3 & 2 & 3 & 0.780 \\
\hline 1 & 5 & 2 & 2 & 1 & \\
\hline \multicolumn{6}{|l|}{ Laterality } \\
\hline Right & 8 & 2 & 3 & 3 & 0.479 \\
\hline Left & 5 & 3 & 1 & 1 & \\
\hline \multicolumn{6}{|l|}{ Nephrectomy } \\
\hline Radical & 11 & 4 & 4 & 3 & 0.603 \\
\hline Partial & 2 & 1 & 0 & 1 & \\
\hline \multicolumn{6}{|l|}{ Histology } \\
\hline Clear cell RCC & 11 & 5 & 2 & 4 & 0.085 \\
\hline Papillary RCC & 2 & 0 & 2 & 0 & \\
\hline \multicolumn{6}{|l|}{ Nuclear grade } \\
\hline $\mathrm{G} 1 / \mathrm{G} 2$ & 12 & 4 & 4 & 4 & 0.449 \\
\hline G3 & 1 & 1 & 0 & 0 & \\
\hline \multicolumn{6}{|l|}{ Stage } \\
\hline pT1 & 6 & 3 & 1 & 2 & 0.593 \\
\hline $\mathrm{pT} 2 / \mathrm{pT} 3 / \mathrm{pT} 4$ & 7 & 2 & 3 & 2 & \\
\hline \multicolumn{6}{|l|}{ Lymphovascular invasion } \\
\hline 0 & 2 & 1 & 1 & 0 & 0.603 \\
\hline 1 & 11 & 4 & 3 & 4 & \\
\hline \multicolumn{6}{|l|}{ Lung metastasis } \\
\hline No & 3 & 1 & 2 & 0 & 0.267 \\
\hline Yes & 10 & 4 & 2 & 4 & \\
\hline \multicolumn{6}{|l|}{ Bone metastasis } \\
\hline No & 8 & 2 & 4 & 2 & 0.180 \\
\hline Yes & 5 & 3 & 0 & 2 & \\
\hline \multicolumn{6}{|l|}{ TKIs } \\
\hline Sunitinib & 8 & 4 & 3 & 1 & 0.219 \\
\hline Others & 5 & 1 & 1 & 3 & \\
\hline \multicolumn{6}{|l|}{ Dose intensity (\%) } \\
\hline 100 & 7 & 2 & 2 & 3 & 0.593 \\
\hline$<100$ & 6 & 3 & 2 & 1 & \\
\hline \multicolumn{6}{|l|}{ Previous treatment } \\
\hline No & 2 & 1 & 1 & 0 & 0.603 \\
\hline Yes & 11 & 4 & 3 & 4 & \\
\hline \multicolumn{6}{|l|}{ Previous TKI treatment } \\
\hline No & 8 & 4 & 3 & 1 & 0.219 \\
\hline Yes & 5 & 1 & 1 & 3 & \\
\hline \multicolumn{6}{|c|}{ Previous cytokine treatment } \\
\hline No & 5 & 3 & 1 & 1 & 0.479 \\
\hline Yes & 8 & 2 & 3 & 3 & \\
\hline
\end{tabular}


Table I. Continued.

\begin{tabular}{|c|c|c|c|c|c|}
\hline \multirow[b]{2}{*}{ Clinical characteristics } & \multirow[b]{2}{*}{$\begin{array}{c}\text { Total } \\
(\mathrm{n}=13)\end{array}$} & \multicolumn{3}{|c|}{ Clinical effect ${ }^{\mathrm{a}}$} & \multirow[b]{2}{*}{ P-value } \\
\hline & & $\begin{array}{c}\text { PR } \\
(n=5)\end{array}$ & $\begin{array}{c}\mathrm{SD} \\
(\mathrm{n}=4)\end{array}$ & $\begin{array}{c}\text { PD } \\
(n=4)\end{array}$ & \\
\hline \multicolumn{6}{|c|}{ Previous mTOR inhibitor treatment } \\
\hline No & 10 & 4 & 3 & 3 & 0.980 \\
\hline Yes & 3 & 1 & 1 & 1 & \\
\hline
\end{tabular}

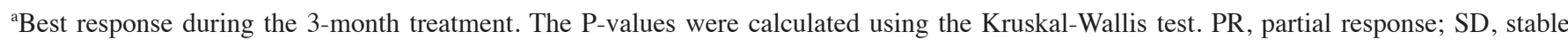
disease; PD, progressive disease; RCC, renal cell carcinoma; mTOR, mammalian target of rapamycin.

IL-10, IL-12, IL-13, IL-15, IL-17, eotaxin, basic fibroblast growth factor, granulocyte colony-stimulating factor, granulocyte macrophage colony-stimulating factor (GM-CSF), interferon- $\gamma$ (IFN- $\gamma)$, IFN- $\gamma$-induced protein 10 , monocyte chemoattractant protein-1, macrophage inflammatory protein (MIP)-1 $\alpha$, platelet-derived grow th factor (PDGF)-BB, MIP-1 $\beta$, regulated on activation, normal T-cell expressed and secreted, tumor necrosis factor- $\alpha$ and VEGF were measured twice by BioPlex Pro Human Cytokine 27 Plex assay (M50-0KCAF0Y; Bio-Rad, Hercules, CA, USA). The assay was performed according to the manufacturer's instructions. Briefly, plasma was centrifuged at $15,000 \times \mathrm{g}$ for $10 \mathrm{~min}$ at $4^{\circ} \mathrm{C}$. The samples were then incubated with microbeads labeled with specific antibodies to one of the aforementioned cytokines for $60 \mathrm{~min}$. Following a washing step, the beads were incubated with the detection antibody cocktail, with each antibody specific to a single cytokine, for $30 \mathrm{~min}$. After another washing step, the beads were incubated with streptavidin-phycoerythrin for $10 \mathrm{~min}$, washed again and the concentration of each cytokine was determined using the array reader. The samples were tested in duplicate on a 96-well plate alongside the standard curve used to generate the results. Unknown concentrations were calculated from a standard curve generated from Bio-Rad supplied standards.

Statistical analysis. The correlation between clinical and cytokine data was analyzed by analysis of variance (ANOVA) and Tukey-Kramer's test using JMP software, version 10.0.0 (SAS, Institute, Cary, NC, USA).

This study was approved by the Institutional Ethics Committee of the Faculty of Medicine and Graduate School of Medicine of the University of Tokyo (no. H22-23-400).

\section{Results}

Patient characteristics. A total of 13 patients ( 8 treated with sunitinib, 1 with sorafenib and 4 with axitinib), including 11 men and 2 women, with a median age of 63 years (range, 50-77 years), were recruited in this study (Table I). The performance status was 0 in 8 and 1 in 5 cases. Eight tumors were located in the right and 5 in the left kidney. Radical nephrectomy was performed in 11 and partial nephrectomy in 2 patients. Histologically, the tumors were diagnosed as 11 clear cell RCCs and 2 papillary RCCs. All the patients had

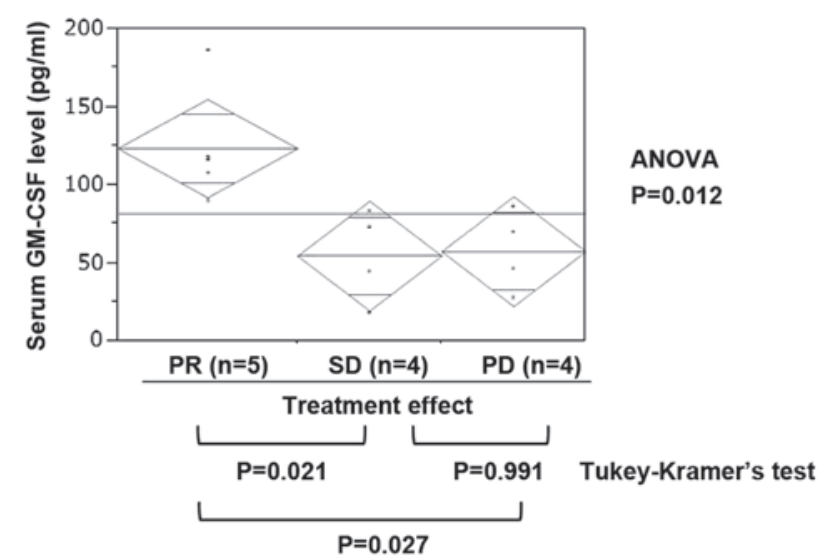

Figure 1. Comparison of serum granulocyte macrophage colony-stimulating factor (GM-CSF) levels among patients who achieved partial response (PR), stable disease (SD) or exhibited progressive disease (PD) after treatment with tyrosine kinase inhibitors. ANOVA, analysis of variance.

developed metastasis, with the most common metastatic site being the lung (10 cases), followed by bone ( 5 cases).

Treatment. Two cases received TKI treatment as first-line therapy. Previous systemic treatment included TKIs in 5, mammalian target of rapamycin (mTOR) inhibitors in 3 and cytokines in 8 patients. PR was achieved in 5 cases (38\%), SD in $4(30 \%)$ and PD developed in 4 cases $(30 \%)$. The dose was reduced in 6 patients $(46 \%)$ due to adverse events.

GM-CSF plasma levels by treatment response. No clinical parameters exhibited a significant correlation with treatment effect (Table I). Among the 27 investigated cytokines, the plasma GM-CSF level in PR cases was significantly higher compared to that in cases with SD or PD (Fig. 1, ANOVA, $\mathrm{P}=0.012$; Tukey-Kramer's test: $\mathrm{PR}$ vs. $\mathrm{SD}, \mathrm{P}=0.021$; $\mathrm{PR}$ vs. $\mathrm{PD}$, $\mathrm{P}=0.027$; and SD vs. $\mathrm{PD}, \mathrm{P}=0.991)$. The IL-6 level was higher in PD cases, but the difference was not statistically significant (Table II, $\mathrm{P}=0.141$ ).

\section{Discussion}

We demonstrated that plasma GM-CSF may be a predictive marker of the response to TKI treatment. Thus far, only a few studies demonstrated the clinical utility of GM-CSF. The 
Table II. Correlation between the clinical effect of tyrosine kinase inhibitors and cytokine levels in patients with metastatic renal cancer.

\begin{tabular}{|c|c|c|c|c|}
\hline \multirow[b]{2}{*}{ Cytokines } & \multicolumn{3}{|c|}{ Clinical effect } & \multirow[b]{2}{*}{ P-value } \\
\hline & PR & $\mathrm{SD}$ & PD & \\
\hline GM-CSF & $123 \pm 36$ & $54 \pm 29$ & $57 \pm 25$ & 0.012 \\
\hline IL-1 $\beta$ & $3.8 \pm 4.6$ & $1.9 \pm 1.2$ & $1.6 \pm 0.2$ & 0.494 \\
\hline IL-1ra & $103 \pm 98$ & $57 \pm 43$ & $60 \pm 22$ & 0.536 \\
\hline IL-2 & $5.2 \pm 2$ & $4.8 \pm 3.1$ & $5 \pm 3$ & 0.971 \\
\hline IL-4 & $5.6 \pm 2.3$ & $4.8 \pm 1.8$ & $5.1 \pm 2.2$ & 0.864 \\
\hline IL-5 & $1.1 \pm 1.4$ & $0.7 \pm 0.8$ & $0.6 \pm 0.8$ & 0.791 \\
\hline IL-6 & $6 \pm 2.3$ & $5 \pm 2.6$ & $12 \pm 8.9$ & 0.141 \\
\hline IL-7 & $5.3 \pm 1.9$ & $4.8 \pm 4.9$ & $3.1 \pm 2.2$ & 0.605 \\
\hline IL-8 & $25 \pm 13$ & $29 \pm 33$ & $19 \pm 12$ & 0.779 \\
\hline IL-9 & $44 \pm 12$ & $26 \pm 8.8$ & $29 \pm 15$ & 0.125 \\
\hline IL-10 & $4.2 \pm 2.9$ & $3.4 \pm 1.1$ & $6.4 \pm 5.7$ & 0.525 \\
\hline IL-12 & $19 \pm 17$ & $17 \pm 15$ & $32 \pm 37$ & 0.658 \\
\hline IL-13 & $5.2 \pm 3.9$ & $5.1 \pm 3.1$ & $5.1 \pm 2.4$ & 0.990 \\
\hline IL-15 & $5 \pm 1.6$ & $3.6 \pm 2.3$ & $4.2 \pm 0.6$ & 0.479 \\
\hline IL-17 & $56 \pm 15$ & $41 \pm 16$ & $59 \pm 41$ & 0.613 \\
\hline Eotaxin & $183 \pm 152$ & $128 \pm 126$ & $112 \pm 61$ & 0.667 \\
\hline FGF-basic & $51 \pm 14$ & $42 \pm 12$ & $55 \pm 22$ & 0.554 \\
\hline G-CSF & $66 \pm 19$ & $52 \pm 18$ & $59 \pm 13$ & 0.527 \\
\hline IFN- $\gamma$ & $610 \pm 893$ & $207 \pm 94$ & $178 \pm 21$ & 0.462 \\
\hline IP-10 & $2,381 \pm 1,857$ & $1,386 \pm 749$ & $1,906 \pm 1,432$ & 0.616 \\
\hline MCP-1 & $82 \pm 68$ & $41 \pm 16$ & $47 \pm 22$ & 0.388 \\
\hline MIP-1 $\alpha$ & $2.9 \pm 1.1$ & $7.7 \pm 12$ & $2.9 \pm 1.7$ & 0.561 \\
\hline PDGF-BB & $309 \pm 306$ & $862 \pm 146$ & $213 \pm 128$ & 0.508 \\
\hline MIP-1 $\beta$ & $178 \pm 43$ & $174 \pm 141$ & $128 \pm 79$ & 0.703 \\
\hline RANTES & $3,364 \pm 138$ & $2,630 \pm 763$ & $2,679 \pm 771$ & 0.523 \\
\hline TNF- $\alpha$ & $88 \pm 92$ & $62 \pm 47$ & $43 \pm 6.9$ & 0.580 \\
\hline VEGF & $108 \pm 62$ & $122 \pm 79$ & $165 \pm 143$ & 0.683 \\
\hline
\end{tabular}

The results are expressed as mean \pm standard deviation $(\mathrm{pg} / \mathrm{ml})$ and the P-values were calculated using analysis of variance. PR, partial response; SD, stable disease; $\mathrm{PD}$, progressive disease; GM-CSF, granulocyte macrophage colony-stimulating factor; IL, interleukin; FGF, fibroblast grow th factor; G-CSF, granulocyte colony-stimulating factor; IFN- $\gamma$, interferon- $\gamma$; IP-10, IFN- $\gamma$-induced protein 10; MCP-1, monocyte chemoattractant protein-1; MIP, macrophage inflammatory protein; RANTES, regulated on activation, normal T-cell expressed and secreted; PDGF, platelet-derived growth factor; TNF- $\alpha$, tumor necrosis factor- $\alpha$; VEGF, vascular endothelial growth factor.

plasma GM-CSF level was found to be higher in cervical cancer patients compared to healthy controls (13), while in another study GM-CSF was undetectable in non-cancer patients (14).

GM-CSF promotes the differentiation and expansion of myeloid-derived suppressor cells (MDSCs) $(15,16)$. Antigen-specific CD8 ${ }^{+}$T-cell tolerance, induced by MDSCs, is known to be one of the main mechanisms of tumor escape (17). Knockdown of GM-CSF in tumor cells may reverse the cytotoxicity to CD8 T lymphocytes: Dolcetti et al (15) found that lack of GM-CSF release from 4T1 mammary carcinoma cells reduced the accumulation of Gr- $1^{\text {int/low }}$ MDSC subsets and successfully inhibited tumor-induced tolerance in mice. Similarly, Serafini et al (16) demonstrated that inhibition of MDSC function abrogates the proliferation of regulatory $\mathrm{T}$ cells and tumor-induced tolerance in antigen-specific T cells, using the A20 B-cell lymphoma model in vitro and in vivo. However, TKIs may reduce the number of MDSCs in the tumor and normalize T-lymphocyte function: Xin et al (18) demonstrated that sunitinib directly induced RCC tumor cell apoptosis through Stat3 inhibition, which was accompanied by a reduction in MDSCs and tumor-infiltrating regulatory $\mathrm{T}$ cells.

These reports suggest that high levels of plasma GM-CSF may promote the function of MDSCs and escape of tumor cells from the host immune system. In patients with high GM-CSF levels, TKIs may decrease the function of MDSCs that is upregulated by GM-CSF and reverse the cytotoxicity of regulatory $\mathrm{T}$ lymphocytes directly or indirectly, which may lower tumor-induced tolerance and result in favorable treatment effects.

In our study, VEGF was not found to be significantly associated with treatment effect, contrary to previous reports $(4,5)$. GM-CSF was reported to induce VEGF release from the epithelium, resulting in the promotion of carcinogenesis: Wang et al (19) demonstrated that, in a colitis-associated cancer model, blocking GM-CSF activity in vivo significantly decreased epithelial release of VEGF and abrogated cancer formation. In the plasma, GM-CSF, which is upstream of VEGF, may be a more sensitive biomarker for metastatic RCC treatment compared to VEGF.

As regards other biomarkers, Tran et al (20) screened pretreatment cytokines and angiogenic factors in patients with metastatic RCC who received pazopanib treatment and found that high IL-6 was predictive for unfavorable progression-free survival. In our study, IL-6 was also higher in PD cases, but the difference was not statistically significant.

This study had certain limitations. First, this was a single-institution study; and second, our sample size was limited.

In conclusion, high pre-treatment plasma levels of GM-CSF, which is an inducer of immune tolerance, were significantly associated with a favorable response of metastatic RCC to TKI treatment. The result suggests the potential of GM-CSF as a predictive biomarker of the response to TKI treatment. However, further investigation is required to determine the effects of TKIs on abrogating cancer immune tolerance.

\section{References}

1. Siegel R, Naishadham D and Jemal A: Cancer statistics, 2012. CA Cancer J Clin 62: 10-29, 2012.

2. Motzer RJ, Hutson TE, Tomczak P, et al: Sunitinib versus interferon alfa in metastatic renal-cell carcinoma. N Engl J Med 356: 115-124, 2007.

3. Escudier B, Eisen T, Stadler WM, et al; TARGET Study Group: Sorafenib in advanced clear-cell renal-cell carcinoma. N Engl J Med 356: 125-134, 2007.

4. Shoji S, Nakano M, Sato H, Tang XY, Osamura YR, Terachi T, Uchida $\mathrm{T}$ and Takeya K: The current status of tailor-made medicine with molecular biomarkers for patients with clear cell renal cell carcinoma. Clin Exp Metastasis 31: 111-134, 2013. 
5. Deprimo SE, Bello CL, Smeraglia J, Baum CM, Spinella D, Rini BI, Michaelson MD and Motzer RJ: Circulating protein biomarkers of pharmacodynamic activity of sunitinib in patients with metastatic renal cell carcinoma: modulation of VEGF and VEGF-related proteins. J Transl Med 5: 32, 2007.

6. Rini BI, Cohen DP, Lu DR, Chen I, Hariharan S, Gore ME, Figlin RA, Baum MS and Motzer RJ: Hypertension as a biomarker of efficacy in patients with metastatic renal cell carcinoma treated with sunitinib. J Natl Cancer Inst 103: 763-773, 2011.

7. Clemons J, Gao D, Naam M, Breaker K, Garfield D and Flaig TW: Thyroid dysfunction in patients treated with sunitinib or sorafenib. Clin Genitourin Cancer 10: 225-231, 2012.

8. Wongkajornsilp A, Wamanuttajinda V, Kasetsinsombat K, Duangsa-ard S, Sa-ngiamsuntorn K, Hongeng $\mathrm{S}$ and Maneechotesuwan K: Sunitinib indirectly enhanced anti-tumor cytotoxicity of cytokine-induced killer cells and $\mathrm{CD}^{+}{ }^{+} \mathrm{CD} 56^{+}$ subset through the co-culturing dendritic cells. PLoS One 8: e78980, 2013.

9. Gu Y, Zhao W, Meng F, Qu B, Zhu X, Sun Y, Shu Y and Xu Q: Sunitinib impairs the proliferation and function of human peripheral $\mathrm{T}$ cell and prevents T-cell-mediated immune response in mice. Clin Immunol 135: 55-62, 2010.

10. Adotevi O, Pere H, Ravel P, et al: A decrease of regulatory T cells correlates with overall survival after sunitinib-based antiangiogenic therapy in metastatic renal cancer patients. J Immunother 33: 991-998, 2010.

11. Rini BI, Escudier B, Tomczak P, et al: Comparative effectiveness of axitinib versus sorafenib in advanced renal cell carcinoma (AXIS): a randomised phase 3 trial. Lancet 378: 1931-1939, 2011.

12. Eisenhauer EA, Therasse P, Bogaerts J, et al: New response evaluation criteria in solid tumours: revised RECIST guideline (version 1.1). Eur J Cancer 45: 228-247, 2009.
13. Lawicki S, Bedkowska GE, Gacuta-Szumarska E, Knapp P and Szmitkowski M: Pretreatment plasma levels and diagnostic utility of hematopoietic cytokines in cervical cancer or cervical intraepithelial neoplasia patients. Folia Histochem Cytobiol 50: 213-219, 2012.

14. Biancotto A, Wank A, Perl S, Cook W, Olnes MJ, Dagur PK, Fuchs JC, Langweiler M, Wang E and McCoy JP: Baseline levels and temporal stability of 27 multiplexed serum cytokine concentrations in healthy subjects. PLoS One 8: e76091, 2013.

15. Dolcetti L, Peranzoni E, Ugel S, et al: Hierarchy of immunosuppressive strength among myeloid-derived suppressor cell subsets is determined by GM-CSF. Eur J Immunol 40: 22-35, 2010.

16. Serafini P, Mgebroff S, Noonan K and Borrello I: Myeloid-derived suppressor cells promote cross-tolerance in B-cell lymphoma by expanding regulatory T cells. Cancer Res 68: 5439-5449, 2008.

17. Nagaraj S, Gupta K, Pisarev V, Kinarsky L, Sherman S, Kang L, Herber DL, Schneck J and Gabrilovich DI: Altered recognition of antigen is a mechanism of $\mathrm{CD} 8^{+} \mathrm{T}$ cell tolerance in cancer. Nat Med 13: 828-835, 2007.

18. Xin H, Zhang C, Herrmann A, Du Y, Figlin R and $\mathrm{Yu} \mathrm{H}$ : Sunitinib inhibition of Stat3 induces renal cell carcinoma tumor cell apoptosis and reduces immunosuppressive cells. Cancer Res 69: 2506-2513, 2009.

19. Wang Y, Han G, Wang K, et al: Tumor-derived GM-CSF promotes inflammatory colon carcinogenesis via stimulating epithelial release of VEGF. Cancer Res 74: 716-726, 2014.

20. Tran HT, Liu Y, Zurita AJ, et al: Prognostic or predictive plasma cytokines and angiogenic factors for patients treated with pazopanib for metastatic renal-cell cancer: a retrospective analysis of phase 2 and phase 3 trials. Lancet Oncol 13: 827-837, 2012. 